\title{
Assessment of eating habits among adolescent Nigerian urban secondary schoolgirls
}

\author{
Alphonsus N Onyiriuka ${ }^{1}$, Amarabia N Ibeawuchi ${ }^{1}$, Rita C Onyiriuka ${ }^{2}$
}

Sri Lanka Journal of Child Health, 2013; 42(1): 20-26

\begin{abstract}
Background: Eating habits are associated with the occurrence of obesity. In adolescence, eating habits differ greatly from that of any other phase of life.
\end{abstract}

Objective: To describe the eating habits of adolescent urban secondary schoolgirls in Benin City, Nigeria.

Methods: In this school-based cross-sectional study, data were obtained on the eating pattern and habits of adolescent urban public school girls, aged 12-19 years, using a structured anonymous-selfadministered questionnaire. Information was obtained on frequencies of skipping meals, reasons for skipping meals, food choices as well as sociodemographic characteristics of participants. All the students in 2 randomly selected girls' schools formed the study population. Data were entered directly from the pre-coded questionnaire. Statistical analysis was performed using the SPSS for Windows version 15.0.

Results: Total study population in the 2 schools was 2,166 of which 2,097 (97\%) students participated in the study. Mean age of the participants was $14.8 \pm 1.9$ years $(95 \% \mathrm{CI}=14.7-14.9)$. Fifty three percent were from families of middle socio-economic status, $85 \%$ of them living with their parents. Among the participants, 1,009 (48\%) admitted skipping at least one meal fortnightly. Of the 3 main meals, breakfast was most frequently skipped (46\%) and dinner least frequently skipped $(22 \%)$. Frequency of skipping meals was $30 \%, 50 \%$ and $59 \%$ among participants less than 14 years old, 14-16 years old and above 16 years old respectively $(\mathrm{p}<0.001)$. The 2 main reasons cited by participants for skipping breakfast were lack of appetite and time. Only $15 \%$ of the participants consumed fruits and vegetables daily. Sixty percent of the participants consumed fast foods with $76 \%$ of them consuming fast foods along with soft drinks.

\footnotetext{
${ }^{1}$ Department of Child Health, University of Benin Teaching Hospital, Benin City, Nigeria, ${ }^{2}$ Department of Economics and Statistics, School of Postgraduate Studies, University of Benin, Benin City, Nigeria
}

(Received on 13 June 2012: Accepted after revision on 24 August 2012)
Conclusion: Meal skipping, consumption of fast foods along with soft drinks and low consumption of fruits and vegetables were the main eating habits displayed by adolescent urban schoolgirls in Benin City, Nigeria.

(Key words: Adolescent urban school girls; eating habits; Nigeria)

\section{Introduction}

Obesity in childhood and adolescence is an emerging major public health problem, associated with a substantial loss of quality of life and social stigmatization which may trigger or exacerbate depression, anxiety, feeling of low self-esteem and guilt ${ }^{1}$. Although prevalence of obesity is increasing worldwide, it is faster in developing countries due to declining levels of physical activity as well as nutrition transition characterized by a trend towards consumption of a diet high in fat, sugar and refined foods and low in fibre ${ }^{2}$. Dietary practice is a modifiable risk factor for obesity in childhood and adolescence which is ten-fold commoner in girls than boys ${ }^{3}$.

Developmental transition (physical, psychological and social) during adolescence provide a context for development and perpetuation of eating behaviour substantially different from that of other phases of life $\mathrm{if}^{3,4}$. Teenagers do not usually conform to a regular pattern of 3 meals per day, over $50 \%$ of them admitting to eating at least 5 times daily ${ }^{4}$. During adolescence, healthy eating behaviour is a fundamental prerequisite for physical growth, psychosocial development and cognitive performance, as well as prevention of diet-related chronic diseases in adulthood ${ }^{5}$. In this context, unhealthy eating behaviour among adolescents is a serious health issue.

Although the dietary cause of obesity in adolescents is multifactorial, it has been linked to consumption of sugar-sweetened-carbonated drinks ${ }^{6}$, fast foods ${ }^{7}$ and increased snacking ${ }^{8}$. In addition, an increase in the average portion size has been reported as an obesitypromoting factor ${ }^{9}$. Clinical experience, as well as research data, indicates that the eating pattern of 
obese individuals is generally chaotic and characterized by missed meals, snacking and late night bingeing ${ }^{10}$. Despite the availability of reports from both developed and developing countries pointing to the influence of eating pattern on the escalating prevalence of obesity ${ }^{11}$, the eating pattern and habits of adolescents in Nigeria have not received sufficient attention. Adolescents, as a group, are highly receptive to new food products and to fast foods, largely due to peer group influence. As a consequence, the food habits of adolescents are usually dynamic and change with time. Given that prevention is the only viable long-term strategy for tackling obesity in adolescence, there is a need to understand the eating pattern and habits among adolescent school girls.

\section{Objective}

The aim of the present study is to describe the eating habits of adolescent urban secondary school girls in Benin City, Nigeria.

\section{Method}

This descriptive-cross-sectional study was conducted in two public secondary schools for females in Oredo Local Government Area (LGA), Edo State, Nigeria. There are nine public secondary schools in the LGA comprising 4 female-only, 3 co-educational and 2 male-only schools ${ }^{12}$. Consent for the study was obtained from the school authorities. The teachers distributed parental consent forms to parents via students asking permission for their child to participate in the study. Of the four girls' secondary schools, two were randomly selected by ballot. As the survey was designed to include all students in the two schools (schools A and B), no sampling was performed. The principal of each school introduced the authors during morning assembly. Subsequently, the authors addressed the students in their classrooms on the objectives of the study and how to accurately fill the questionnaire. The authors emphasized to the students that the questionnaires were anonymous and that their participation was entirely voluntary.

Data were collected between October and November 2011, using a structured-anonymous-selfadministered questionnaire. The questionnaire was pre-tested on 30 school girls of similar age and class in another girls' only secondary school in the same LGA.

The questionnaire was divided into 2 parts: the first part sought information on socio-demographic data, such as age of participants, number of people in the household, educational status of father and mother, occupation of father and mother, religion and state of origin. The socio-economic status of the parents was determined using the classification suggested by Ogunlesi et $a l^{13}$. This was analyzed by combining the highest educational attainment, occupation and income of the parents (based on the mean income of each educational qualification and occupation). In this Social Classification System, classes I and II represent high social class, class III represents middle social class while classes IV and V represent low social class. In this way, the adolescent girls were categorized into high, middle and low socioeconomic groups.

The second part consisted of questions relating to eating pattern and habits and included questions on number of meals eaten every day, habit of skipping meals, the skipped meals, reasons for skipping meals and the composition of the family at the dining table and eating companions. Meal skipping was assessed by asking the adolescent school girls how often over the past two weeks they had skipped breakfast, skipped lunch and skipped dinner. The habit of skipping meals was assessed by questions on frequency of skipping meals: those who answered "yes" or "sometimes" were regarded as skippers while those who answered "no" were regarded as non-skippers. Other information sought included data on food frequency, such as carbohydrate, proteins, fats and oils, fruits and vegetables, drinks and fast foods.

With regard to food choices the influence of taste, the nutritional values, the popularity, the cost, the time and convenience of preparation of food were assessed. Dietary intake data was obtained on all food items and drinks consumed in the immediate two previous days. In the present study, the recall day was defined as from when the respondent gets up one day until the respondent gets up the next day ${ }^{14}$. A snack is defined as a light food and/or a drink that is consumed outside the main meals of breakfast, lunch and dinner. Main meals refer to breakfast, lunch and dinner.

Data were entered directly from the pre-coded questionnaire. Computer printouts of the data were reviewed for any information that was out of range. The statistical analysis was performed using SPSS for Windows version 15.0. Descriptive statistics such as frequencies, means, ratios, standard deviations, confidence intervals and percentages were used to describe the variables. 


\section{Results}

At the time of this survey, a total of 2,166 school girls (1,394 in school A and 772 in school B) were attending the two public, non-boarding girls' secondary schools in the LGA. Seven students (5 from school A and 2 from school B) declined to participate. Questionnaires of 62 students were excluded from the final analysis because they were incompletely filled, thereby leaving a total of 2,097 questionnaires for data analysis. Thus the response rate was $97 \%$. Since students in both schools had similar socio-demographic characteristics, analysis of data was carried out for the 2,097 school girls. Among the participants, $82.6 \%, 14.8 \%$ and $2.6 \%$ were from Christian, Muslim and Traditional Religion families respectively. Based on the state of origin and the religion, the eating pattern did not differ.

Socio-demographic characteristics of the participants are depicted in Table 1.

Table 1: Socio-demographic characteristics of participants $(n=2097)$

\begin{tabular}{|l|c|c|}
\hline \multicolumn{1}{|c|}{ Socio-demographic parameter } & Number (\%) & Mean \pm SD(95\% CI) \\
\hline Age groups & $469(22.4)$ & \\
Below 14 years & $1108(52.8)$ & $14.8 \pm 1.9$ years (14.7-14.9) \\
14-16 years & $520(24.8)$ & \\
17-19 years & $281(13.4)$ & \multirow{2}{*}{$4.9 \pm 1.4(4.6-5.0)$} \\
\hline Household members & $1474(70.3)$ & \\
2-4 persons & $342(16.3)$ & \\
5-7 persons & & $1103(52.6)$ \\
8 or more persons & $258(12.3)$ & \\
\hline Socio-economic status (SES) of parents & $1103(52.6)$ & \\
High SES & $763(35.1)$ & \\
Middle SES & $1776(84.7)$ & \\
Low SES & $321(15.3)$ & \\
\hline Living arrangement & & \\
Living with parents & $1613(76.9)$ & \\
Living with guardian & $319(15.2)$ & \\
\hline Eating companions & $165(7.6)$ & \\
Eats with family members & & \\
Eats with peers & & \\
Eats alone & & \\
\hline
\end{tabular}

Slightly more than half of the participants belonged to the age group 14-16 years. Majority of participants lived with family members and over two-thirds in households with 5-7 members. Just over half the participants came from families of the middle socioeconomic status. Types of dietary practice by the participants are displayed in Table 2

Table 2: Frequency of consumption of various food groups among adolescent school girls $(n=2097)$

\begin{tabular}{|c|c|c|c|}
\hline \multirow[t]{2}{*}{ Food groups } & \multicolumn{3}{|c|}{ Frequency of consuming different food groups per week } \\
\hline & $\begin{array}{c}\text { Daily } \\
\text { Number (\%) }\end{array}$ & $\begin{array}{l}\text { 4-6 times/week } \\
\text { Number (\%) }\end{array}$ & $\begin{array}{c}\text { 1-3 times/week } \\
\text { Number (\%) }\end{array}$ \\
\hline Starchy food & 1879(89.6) & $218(10.4)$ & $0(0)$ \\
\hline Fruit and vegetables & $319(15.2)$ & 694(33.1) & 1084(51.7) \\
\hline Milk and dairy products & $170(08.1)$ & $220(10.5)$ & 1707(81.4) \\
\hline Meat and alternatives & $400(19.1)$ & $665(31.7)$ & 1032(49.2) \\
\hline Sugary, fatty, oily foods & $864(41.2)$ & $996(47.5)$ & $237(11.3)$ \\
\hline Soft drink & 1231(58.7) & $472(22.5)$ & 394(18.8) \\
\hline Canned fruit juice & $91(04.3)$ & $226(10.8)$ & $1780(84.9)$ \\
\hline
\end{tabular}


Starchy food was the most frequently consumed food item and milk/dairy products the least consumed food item. More than half the participants consumed soft drinks daily. The distributions of size of soft drink preferred by the participants were $46.5 \%$ for the small size $(350 \mathrm{ml})$ and $53.5 \%$ for the large size (500 $\mathrm{ml})$.

Among the participants, 829 (40\%) were not choosy on the types of food, eating any available food. Six hundred and eight participants (29\%) admitted trying to eat less to lose weight but they did not consume any specific diet. Frequency of various determinants of choice of food among participants were: taste (48\%), nutritional value (18\%), popularity of the food (24\%), time and convenience (31\%), available family meals $(55 \%)$. Cost was a major determinant $(52 \%)$ in the selection of fast foods. Only 87 participants (4\%) consumed dietary supplements (mainly multivitamins and ferrous sulphate) and that was on the advice of parents. The family got together for meals in $34 \%$ with the father being the most frequently missing member.

Among the participants, 1009 (48\%) were skippers (skipped at least one meal) and 1088 (52\%) were non-skippers. Frequency of main meal skipping among the participants is shown in Table 3.

Table 3: Frequency of main meal skipping among adolescent school girls $(n=2097)$

\begin{tabular}{|l|c|c|}
\hline Main meal & $\begin{array}{c}\text { Non-skippers } \\
\text { No.* (\%) }\end{array}$ & $\begin{array}{c}\text { Skippers } \\
\text { No.* (\%) }\end{array}$ \\
\hline Breakfast & $1,126(53.7)$ & $971(46.3)$ \\
\hline Lunch & $1,460(69.6)$ & $637(30.4)$ \\
\hline Dinner & $1,646(78.5)$ & $451(21.5)$ \\
\hline
\end{tabular}

* Some respondents skipped more than one main meal

Breakfast was the most frequently skipped meal and dinner the least. The ratio of frequency of skipping breakfast, lunch and dinner was: 2.2:1.4:1. Among the skippers, $53 \%, 48 \%$ and $61 \%$ ate with family members, peers and alone respectively. With regard to age, among the 1,009 skippers, frequency of meal skipping was as follows: below 14 years 30\%, 14-16 years $50 \%$ and over 16 years $60 \%$. Frequency of meal skipping was significantly more in the over 16year old participants compared to the below 14-year old participants $\left(X^{2}=88.57 ; \mathrm{P}<0-001\right)$.

Reasons for skipping main meals among adolescent school girls are shown in Table 4
Table 4: Reasons for skipping main meals among adolescent school girls $(n=1009)$

\begin{tabular}{|l|c|}
\hline \multicolumn{1}{|c|}{ Reasons given by respondents } & No.* (\%) \\
\hline Breakfast & $566(56.1)$ \\
Lack of appetite in the morning & $379(37.6)$ \\
Lack of time & $215(21.3)$ \\
Easy to prepare food not available & $178(17.6)$ \\
Self-perceived overweight & $128(12.7)$ \\
Fasting for religious reasons & \\
\hline Lunch & $436(43.2)$ \\
Did not like available food & $361(35.8)$ \\
Lack of appetite & $248(24.6)$ \\
Angry with mother/father & $221(21.9)$ \\
Ate snacks on the way from school & $103(10.2)$ \\
Fasting for religious reasons & \\
\hline Dinner & $337(33.4)$ \\
Did not like available food & $320(31.7)$ \\
Lack of appetite & $207(20.5)$ \\
Angry with mother/father & $189(18.7)$ \\
Ate lunch late & $133(13.2)$ \\
Slept off & $86(8.5)$ \\
Fasting for religious reasons &
\end{tabular}

*Some respondents cited more than one reason

The two leading reasons for skipping breakfast were lack of appetite in the morning and lack of time.

The frequency of consumption of fast foods is depicted in Table 5.

Table 5: Frequency of consumption of fast foods among adolescent school girls $(n=2097)$

\begin{tabular}{|l|c|}
\hline Fast food consumption pattern & Number* (\%) \\
\hline Eats fast foods & $1262(60.2)$ \\
Yes & $835(39.8)$ \\
*Rarely or not & $266(12.7)$ \\
\hline Frequency of eating fast food & $388(18.5)$ \\
Daily & $1443(68.8)$ \\
4-6 times/week & $633(30.2)$ \\
1 -3 times/week & $1464(69.8)$ \\
\hline Usual place of eating fast food & \\
At home & \\
Outside home & $1445(68.9)$ \\
\hline Type of fast foods consumed & $455(21.7)$ \\
Meat pie/egg & \\
buns/cake/doughnut & $197(09.4)$ \\
Ice cream & \\
Jollof rice/fried rice/fried meat/ & \\
Turkey/chicken & \\
*Rarely = less than once fortnightly &
\end{tabular}

Over three-quarter (76\%) of the adolescents usually consumed fast food along with soft drinks. 


\section{Discussion}

In the present study, skipping of meals was observed as a common eating habit among adolescent school girls. Several previous studies have reported similar findings ${ }^{6,15}$. Consistent with previous studies ${ }^{16}$, breakfast was the most frequently skipped main meal in the present study. Older adolescent school girls tended to skip breakfast more often than their younger schoolmates, suggesting that the prevalence of breakfast skipping increased with transition from adolescence to full adulthood. Niemeier et al have reported a similar finding ${ }^{17}$. In that study, they demonstrated that breakfast skipping was linked to weight gain from adolescence to adulthood. Skipping of meals represents an unhealthy eating habit among adolescent school girls in Benin City, Nigeria. This view is reinforced by studies which indicated that skipping of breakfast significantly decreased daily energy, calcium and protein intakes ${ }^{18}$. Some studies have linked skipping of meals with occurrence of overweight and obesity ${ }^{17}$. Studies have also linked meal skipping behaviour, particularly breakfast skipping, to adverse adolescents' nutritional status, impaired cognitive performance and reduced quality of life ${ }^{19}$. As in other studies ${ }^{20}$, skipping of dinner was the least prevalent. Adolescents who ate alone tended to skip meals more often than their counterparts who either ate with family members or with peers.

In the present study, the leading reasons cited by the participants for skipping breakfast were lack of appetite in the morning and lack of time. This finding is consistent with the results of Soyer et al among adolescent school girls in Turkey ${ }^{21}$. In the present study, self-perceived overweight (18\%) ranked low among the reasons cited by participants for skipping meals. Participants in previous studies have cited body image concerns as one of the reasons for skipping meals, particularly breakfast ${ }^{16}$. Even among the participants who did not skip meals, more than a quarter admitted eating less because of body image concerns.

Socio-economic status (SES) of the families of the participants did not appear to influence the prevalence of meal skipping in the present study, suggesting that socio-economic differences are less pronounced during adolescence than during any other phase of life. This finding with regard to SES and meal skipping is consistent with the results of the study by Soyer $e t a l^{21}$.The apparent lack of influence of SES on meal skipping among adolescent school girls may be explained by the homogenizing effects of school experiences as well as youth culture. Data from the present study indicates that significantly more adolescent school girls over 16 years of age were more likely to skip meals than their schoolmates who were less than 14 years old $(\mathrm{P}<0.001)$. Similar observations have been reported previously ${ }^{16}$. A possible explanation may be that older adolescent school girls have a higher degree of body image concerns than their younger counterparts. This view is reinforced by the observation in the present study and previous ones that body image concerns are linked to the practice of meal skipping among adolescent school girls ${ }^{16,21}$.

Data from the present study indicated that there was a high $(90 \%)$ daily consumption of starchy food, well above the $33 \%$ suggested by Hogston and Simpson in their "tilted plate" concept ${ }^{22}$. A tilted plate shows the percentages of food groups that a healthy individual should aim to eat in a day and depicts the percentages of food groups needed for a balanced diet. This finding is not surprising as carbohydrates constitute the staple food in Nigerian communities, whether urban or rural. Similarly, a high daily consumption of carbohydrates was reported among Iranian adolescent school girls ${ }^{15}$. More worrisome is the low daily consumption of fruit and vegetables among adolescent school girls in the present study. A similar finding has been reported from $\operatorname{Iran}^{15}$. A low consumption of fruits and vegetables has been associated with overweight and other long-term adverse effects on health that could not be shown in a cross-sectional study ${ }^{23}$. The present study revealed a high consumption of soft drinks among adolescent school girls, a finding consistent with that of earlier studies $^{6,15}$. Some studies have linked high soft drink consumption rate to poor intake of calcium, vitamin $\mathrm{C}$ and increased risk of bone fractures ${ }^{24}$.

The present study revealed a relatively high consumption of fast food by adolescent school girls. A study among adolescent school girls in Iran has reported a similar finding ${ }^{15}$. One feature of fast food consumption that needs to be highlighted in the present study is that the majority $(76 \%)$ of the adolescents consumed fast food along with soft drinks. This finding is consistent with previous studies among adolescents in Saudi Arabia and Iran ${ }^{15}$. This finding is worrisome in that $69 \%$ of the fast foods consumed by adolescent girls in the present study are energy dense food such as meat pie, egg buns, cake and doughnuts. The fact that soft drinks in themselves have a high glycaemic index and are also energy dense makes this eating practice very unhealthy ${ }^{6}$.

Consistent with previous studies ${ }^{25}$, the choice of fast food among adolescent school girls in the present 
study was influenced by taste, convenience and cost. Again, most fast foods with the qualities of good taste, convenience and low cost usually have a high fat and sugar content and are refined foods, resulting in unhealthy eating practices. Fibre content of fast foods is usually low. This type of dietary practice is considered to be obesity-promoting.

There are some limitations of the present study. Firstly, the present study involved only female adolescents and therefore, the results cannot be generalized to include male adolescents. Secondly, the findings are limited by the sampling location since the participants were derived from secondary schools in one LGA of Edo State and were also located in the urban area. These limitations notwithstanding, this study gives an insight into the dietary and eating behaviour of adolescent school girls in this locality. The strength of the study lies in the large study population which allows for meaningful conclusions. It is suggested that the scope of future studies on the subject should be broadened to include male adolescents, secondary schools in other LGAs of the state as well as adolescents in the rural areas.

\section{Conclusions}

Meal skipping, particularly breakfast, consumption of fast foods along with soft drinks and poor consumption of fruit and vegetables were the main unhealthy eating behaviour among adolescent urban school girls in Benin City, Nigeria.

\section{References}

1. Visscher TL, Seidell JC. The public health impact of obesity. Annual Review of Public Health 2001;22: 355-75.

http://dx.doi.org/10.1146/annurev.publhealth.22. $\underline{1.355}$

2. Ogden CI, Flegal KM, Carrol MD, Johson CL. Prevalence and trends in overweight among US children and adolescents, 1999-2000. Journal of the American Medical Association 2002; 288: $1728-32$. http://dx.doi.org/10.1001/jama.288.14.1728

3. Fosson A, Bryant-Waugh R. Adolescent eating disorders. In: Brook CGD ed. The Practice of Medicine in Adolescence. London: Edward Arnold Publisher: 1995: 249-58.

4. McNaughton SA, Ball K, Mishra GD, Crawford DA. Dietary patterns of adolescents and risk of obesity and hypertension. Journal of Nutrition 2008; 138(2):527-34.

5. Quatromoni PA, Copenhafer DL, D'Agostino RB, Millen BE. Dietary patterns predict the development of overweight in women: the Framingham Nutrition Studies. Journal of the American Dietetic Association 2002; 102:12406.

6. James J, Thomas P, Cavan D, Kerr D. Preventing childhood obesity by reducing consumption of carbonated drinks: cluster randomized controlled trial. British Medical Journal 2004; 328:1237-9. http://dx.doi.org/10.1136/bmj.38077.458438.EE

7. Washi SA, Ageib MB. Poor diet quality and food habits are related to impaired nutritional status in 13-to-18-year-old adolescents in Jeddah. Nutrition Research 2010; 30(8):527-34. http://dx.doi.org/10.1016/j.nutres.2010.07.002

8. Jahns L, Siega-Riz AM, Popkin BM. The increasing frequency of snacking among US children from 1977 to 1996. Journal of Pediatrics 2001; 138(4):493-8. http://dx.doi.org/10.1067/mpd.2001.112162

9. Nielsen SJ, Popkin BM. Patterns and trends in food portion sizes, 1977-1998. Journal of the American Medical Association 2003; 289(4): 450-3. http://dx.doi.org/10.1001/jama.289.4.450

10. Carmel J, Musante G. Structured eating: A predictor of weight loss at follow-up. Ecology of Food and Nutrition 1980; 9:87-92. http://dx.doi.org/10.1080/03670244.1980.99905 $\underline{86}$

11. Ackard DM, Neumark-Sztainer D, Story M et al. Overeating among adolescents: prevalence and associations with weight-related characteristics and psychological health. Pediatrics 2003; 111: 67-74.

http://dx.doi.org/10.1542/peds.111.1.67

12. Ministry of Education, Benin City. Department of Planning, Research and Statistics. Directory of Pre-primary, Primary, Junior and Senior Secondary Institutions in Edo State, 2006.

13. Ogunlesi TA, Dedeke IOF, Kuponiyi OT. Socioeconomic classification of children attending Specialist Paediatric Centres in Ogun State, 
Nigeria. Nigerian Medical Practitioner 2008; 54(1):21-25.

http://dx.doi.org/10.4314/nmp.v54i1.28943

14. Van Staveren WA, Ocke MC. Estimation of dietary intake. In: Bowman BA, Rusell RM eds. Present Knowledge in Nutrition. 8th ed. Washington DC, International Life Sciences Institute Press, 2001:605-16.

15. Montazerfar F, Karajibani M, Dashipour AR. Evaluation of dietary intake and food patterns of adolescent girls in Sistan and Baluchistan Province, Iran. Journal of Functional Foods in Health and Disease 2012; 2(3):62-71.

16. Chin YS, Nasir MT. Eating behaviors among female adolescents in Kuantan district, Pahang, Malaysia. Pakistan Journal of Nutrition 2009; 8(4):425-32.

http://dx.doi.org/10.3923/pjn.2009.425.432

17. Niemeier HM, RaynorHA, Lloyd-Richardson EE, Rogers ML, Wing RR. Fast food consumption and breakfast skipping: predictors of weight gain from adolescence to adulthood in a nationally representative sample. Journal of Adolescent Health 2006; 39:842-9. http://dx.doi.org/10.1016/j.jadohealth.2006.07.00 $\underline{1}$

18. Miller GD, Forgac R, Cline R, McBean LD. Breakfast benefits children in the US and abroad. Journal of the American College of Nutrition 1998; 17(1):4-6.

19. Gajre NS, Fernandez S, Balekrishina N, Vazir S. Breakfast eating habit and its influence on attention-concentration, immediate memory and school achievement. Indian Pediatrics 2008; 45:824-8.
20. Samuelson G. Dietary habits and nutritional status in adolescents over Europe: An overview of current studies in the Nordic countries. European Journal of Clinical Nutrition 2000; 54:S21-S28.

http://dx.doi.org/10.1038/sj.ejcn.1600980

21. Soyer MT, Ergin I, Gursoy ST. Effects of social determinants on food choice and skipping meals among Turkish adolescents. Asia Pacific Journal of Clinical Nutrition 2008; 17:208-13.

22. Hogston R, Simpsom PM. Foundations of Nursing Practice: Making the Difference. Palgrove: Macmillian, 2002.

23. Bernard L, Lavallee C, Gray-Donald K, Delisle H. Overweight in Cree schoolchildren and adolescents associated with diet, low physical activity, and high television viewing. Journal of the American Dietetic Association 1995; 95:8002. http://dx.doi.org/10.1016/S0002-8223(95)00221$\underline{9}$

24. Harnack L, Stang J, Story M. Soft drink consumption among US children and adolescents: nutritional consequences. Journal of the American Dietetic Association 1999; 99(4):436-41. http://dx.doi.org/10.1016/S0002-8223(99)00106$\underline{6}$

25. Shannon C, Story M, Fulkerson JA, French SA. Factors in the school cafeteria influencing food choices by high school students. Journal of School Health 2002; 72(6):229-34. 